\title{
Pathology of Salmonella choleraesuis Related Respiratory Infection in Piglets, Its Isolation, Identification and Antibiogram
}

\author{
A. Geethika ${ }^{1 *}$, Mammen J. Abraham ${ }^{1}$, N. Divakaran Nair ${ }^{1}$, K. Krithiga ${ }^{1}$ and P.M. Priya ${ }^{2}$ \\ ${ }^{1}$ Department of Veterinary Pathology, College of Veterinary and Animal Sciences, Mannuthy, \\ Thrissur, Kerala - 680 651, India \\ ${ }^{2}$ Department of Veterinary Microbiology, College of Veterinary and Animal Sciences, \\ Mannuthy, Thrissur, Kerala - 680 651, India \\ *Corresponding author
}

\section{A B S T R A C T}

\begin{tabular}{|c|c|}
\hline $\begin{array}{l}\text { Salmonella } \\
\text { choleraesuis, PCR, } \\
\text { Antibiogram, } \\
\text { Odema, Interstitial } \\
\text { pneumonia. }\end{array}$ & $\begin{array}{l}\text { Ninety two piglet carcasses showing respiratory lesion presented to the Department of } \\
\text { Veterinary Pathology, College of Veterinary and Animal Sciences, Mannuthy, Thrissur for } \\
\text { necropsy were selected for detailed pathological and bacteriological studies. Five lung } \\
\text { samples were found to be positive for Salmonella choleraesuis infection based on culture, } \\
\text { morphology, biochemical tests and fliC gene based PCR. Gross lesions of Salmonella } \\
\text { infected piglets revealed severe congestion, oedema, areas of consolidation, extensive } \\
\text { haemorrhage and emphysema in lungs, frothy exudates in tracheal lumen and enlargement }\end{array}$ \\
\hline Arti & \\
\hline $\begin{array}{l}\text { Accepte } \\
26 \text { Sept } \\
\text { Availab } \\
10 \text { Octo }\end{array}$ & $\begin{array}{l}\text { Ings characteristic of interstitial pneumonia were noticed. Bronchial lymph nodes showed } \\
\text { Imphoid depletion and haemorrhages. This study established the prevalence, pathology, } \\
\text { olecular detection S. choleraesuis in respiratory infection in the pig population in } \\
\text { hrissur. }\end{array}$ \\
\hline
\end{tabular}

\section{Introduction}

Salmonella is one of the most important enteric pathogen affecting intensively reared weaned piglets below five months of age. Porcine Salmonella serovars are mainly classified as host restricted serovars typified by $S$. choleraesuis and ubiquitous serovars typified by $S$. typhimurium. $S$. derby and $S$. typhimurium were considered as the most commonly isolated serovars from pigs. The main mode of transmission of Salmonella was considered as faeco-oral route but aerosol transmission was also suggested to be the important route (Fedorka Cray et al., 1995).
Worldwide increase in antimicrobial resistance to non-typhoid Salmonella species has become a major problem for public health concern. Antibiotic resistance cause reduced effect on both conventional and newer antibiotic therapy, thereby aggravating the situation. In a study conducted by Jean et al., (2006) human and swine isolates were shown to have the same pulsotype and they hypothesized that Salmonella transmission from swine to humans caused antibiotic resistance in humans due to the use of antibiotics in veterinary practice at sub 
therapeutic level or as growth promoters in feed. The present study envisaged better understanding of isolation, identification and pathomorphology of $S$. choleraesuis in respiratory infections of piglets which will be helpful in adopting proper therapeutic modalities and initiating better control measures.

\section{Materials and Methods}

Lung samples of piglets showing respiratory lesions which were brought for postmortem examination at the Department of Veterinary Pathology, College of Veterinary and Animal Sciences, Mannuthy, Kerala during a period from January to September, 2016 were collected. Detailed postmortem examination of carcasses showing respiratory lesions was performed. Lung samples were collected in 10 per cent neutral buffered formalin and in sterile Petriplates for histopathology and bacteriological examinations respectively. Salmonella was isolated using MacConkey agar and subjected to biochemical tests using

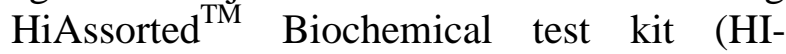
MEDIA).The identification of bacteria was done as per standard protocols prescribed by Bergey's manual (Quinn et al., 1994).

Isolates positive in conventional methods were subjected to fliC based $S$. choleraesuis specific primer as per Chiu et al., (2005). Forward primer 5'-AAG GAA AAG ATC ATG GCA CAA-3' and reverse primer 5'GAA CCC ACC ATC AAT AAC TTT G-3' were used to get an amplicon size of 963bp. Amplification of PCR product was confirmed by one per cent agarose gel electrophoresis. The gel was visualized and documented in a gel documentation system (Bio-Rad laboratories, USA). All positive Salmonella isolates were analyzed for antimicrobial resistance by the disc-diffusion method (Cockerill et al., 2013) using commercially available antibiotic discs (HiMedia laboratories Limited, Mumbai). Representative lung tissues were processed and embedded in paraffin. Tissue sections were taken at 4-5 $\mu \mathrm{m}$ thickness and routine haematoxylin and eosin staining (Bancroft and Cook, 1995) was done and examined under light microscope.

\section{Results and Discussion}

Salmonella choleraesuis is a host restricted serovar producing systemic infection in weaned piglets less than five months of age and characterized by various clinical signs like fever, lethargy, reduced appetite, shallow expiratory dyspnea, huddling behavior and severe scouring. In the present study, five out of 92 samples were positive for $S$. choleraesuis (5.4 per cent). This result was similar to the results of Bahadur et al., (2016), Foley et al., (2008). Bose (2015) reported 60 per cent $S$. choleraesuis infection in lung samples of piglets. This difference in results could be due to different factors like sample size, environmental condition, housing and management of animals, geographical area and virulence of organism.

All isolates were found to be aerobic, gram negative, short rods giving non lactose fermenting colonies of 1-2 $\mathrm{mm}$ in MacConkey Agar and smooth, low convex pink colonies surrounded by pink hue in Brilliant green Agar (Figure 1). The primary genus identification and secondary serovar identification was done using different biochemical (Figure 2) and sugar fermentation tests and the results are presented in Table 1. This was in accordance with Irimie et al., (2010), Sakano et al., (2011) and Bose (2015).

Five bacterial isolates that were positive in conventional methods were subjected to PCR using a primer, specific for S. choleraesuis fliC gene and all the five samples got 
amplified at 963bp (Figure 9). This was in accordance with Chiu et al., (2005) and Bose (2015). Bose (2015) reported extra intestinal isolation of Salmonella from lungs, heart blood and bronchial lymph node of pigs based on conventional and PCR method. Nikbath and Sani (2016) reported that the combination of pre-culture, culture and PCR method can be used for the precise and accurate confirmation of Salmonella. In the present study, an accurate identification of Salmonella choleraesuis was done using conventional and molecular methods.

For identifying the antibiotic sensitivity of $S$. choleraesuis, all five positive isolates were subjected to antibiogram (Figure 4). All the isolates were uniformly sensitive to cefixime, gentamicin, ciprofloxacin, amoxyclav, levofloxacin, ceftriaxone, chloramphenicol, cephalexin, nitrofurantoin, cefotaxime, ciprofloxin and resistance to ampicillin, clindamycin, nalidixic acid, penicillin $\mathrm{G}$ and erythromycin. In a study conducted by Chiu et al., (2002) found only the third generation cephalosporines had the reliable activity against $S$. choleraesuis. Resistance is mainly due to the improper use of antibiotics in animal practice, mutation and also due to interspecies dissemination of resistant plasmids from other organism (Jean et al., 2006).

Table.1 Biochemical and sugar fermentation test of isolates

\begin{tabular}{|c|l|c|}
\hline SI No. & \multicolumn{1}{|c|}{ Test } & Result \\
\hline 1 & ONPG & - \\
\hline 2 & Lysine utilization & + \\
\hline 3 & Ornithine utilization & + \\
\hline 4 & Urease & - \\
\hline 5 & Phenyl alanine deamination test & - \\
\hline 6 & Nitrate reduction & + \\
\hline 7 & H2S production & - \\
\hline 8 & Citrate utilization & + \\
\hline 9 & Voges Proskauer's test & - \\
\hline 10 & Methyl red & + \\
\hline 11 & Indole & - \\
\hline 12 & Malonate utilization & - \\
\hline 13 & Esculin hydrolysis & - \\
\hline 14 & Oxidase & + \\
\hline 15 & Arabinose & + \\
\hline 16 & Xylose & - \\
\hline 17 & Adonitol & + \\
\hline 18 & Rahmnose & - \\
\hline 19 & Cellobiose & + \\
\hline 20 & Melibiose & - \\
\hline 21 & Saccharose & + \\
\hline 22 & Raffinose & + \\
\hline 23 & Trehalose & - \\
\hline 24 & Glucose & - \\
\hline 25 & Lactose & - \\
\hline
\end{tabular}




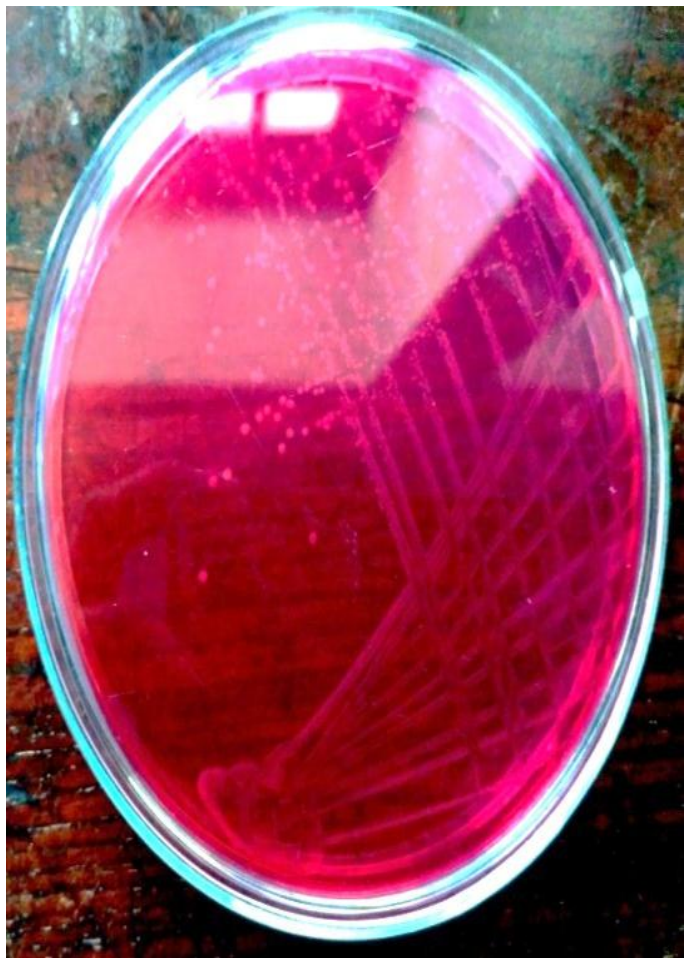

Fig.1 Pink Salmonella colonies in Brilliant green agar

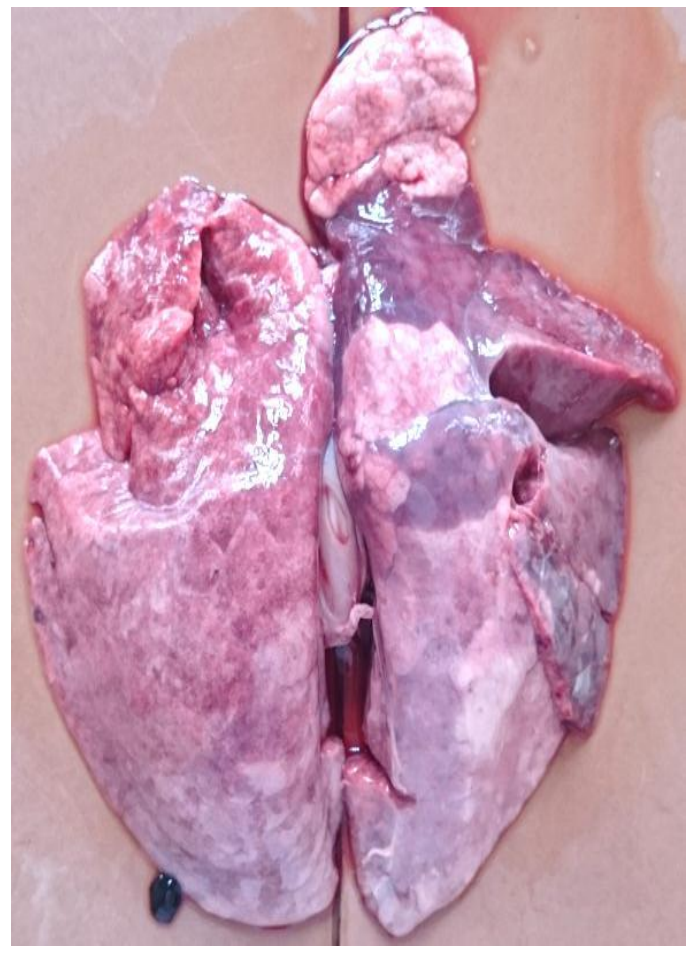

Fig.3 Lung-Unilateral consolidation of lungs

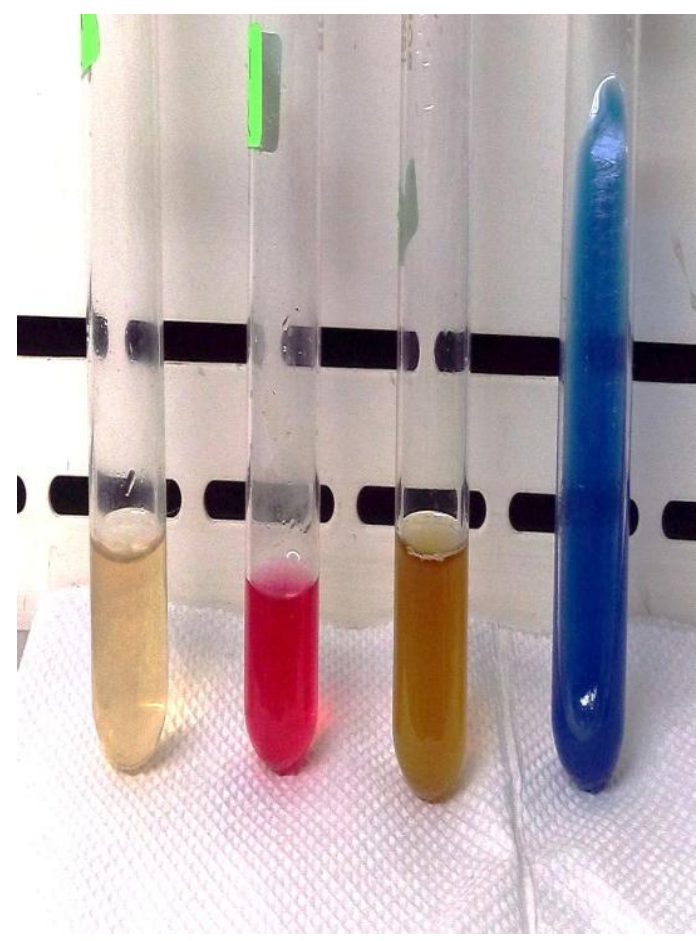

Fig.2 Indole (-), Methyl red (+), Voges Proskauer (-) \&Citrate (+)

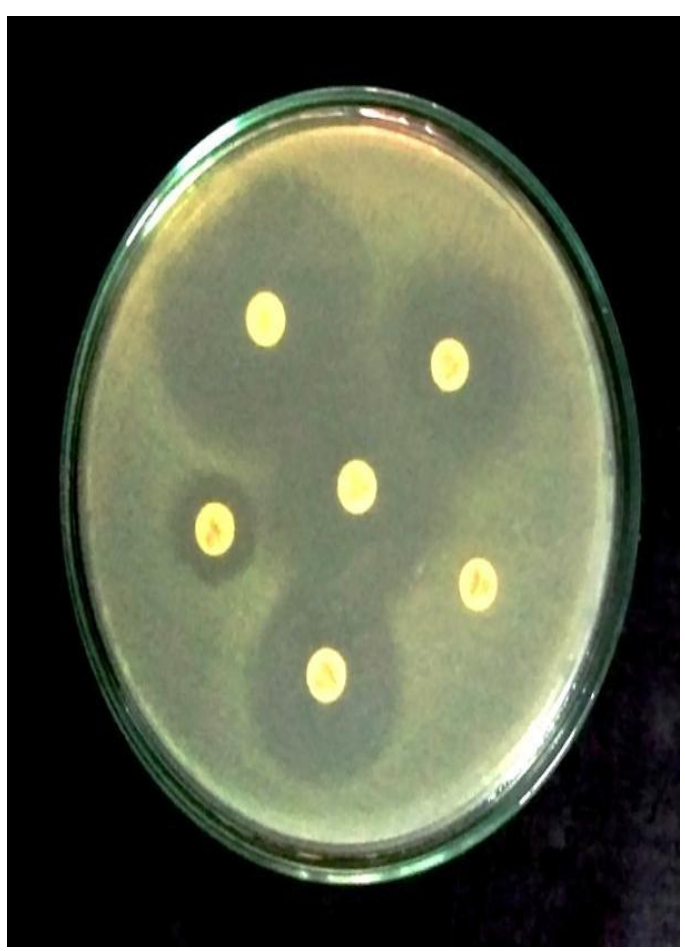

Fig.4 Antibiogram of Salmonella Choleraesuis 


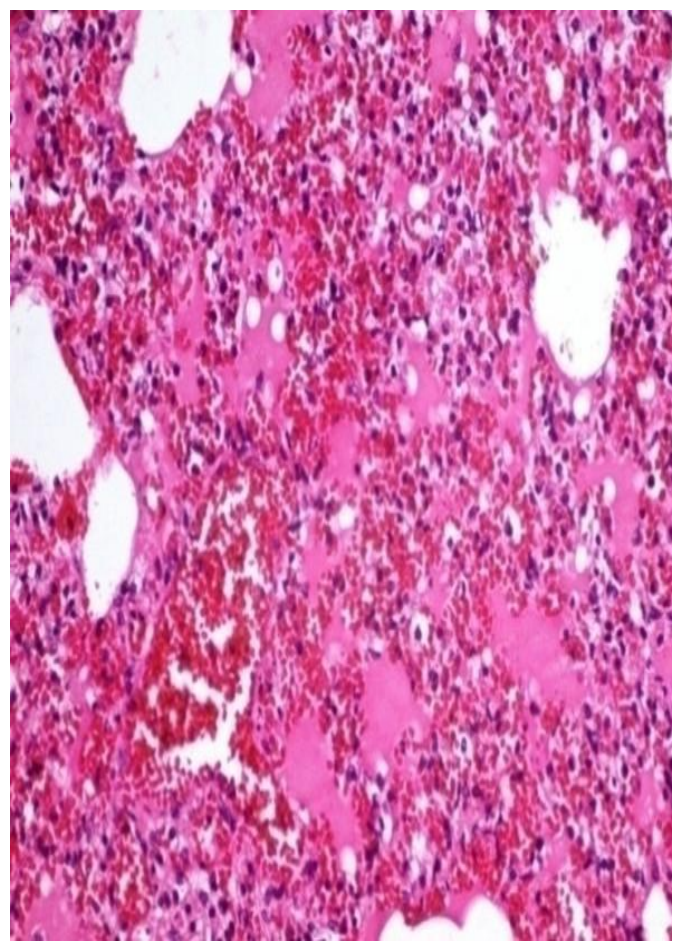

Fig.5 Lung-Pulmonary edema (H\&E $\mathrm{x} 400$ )

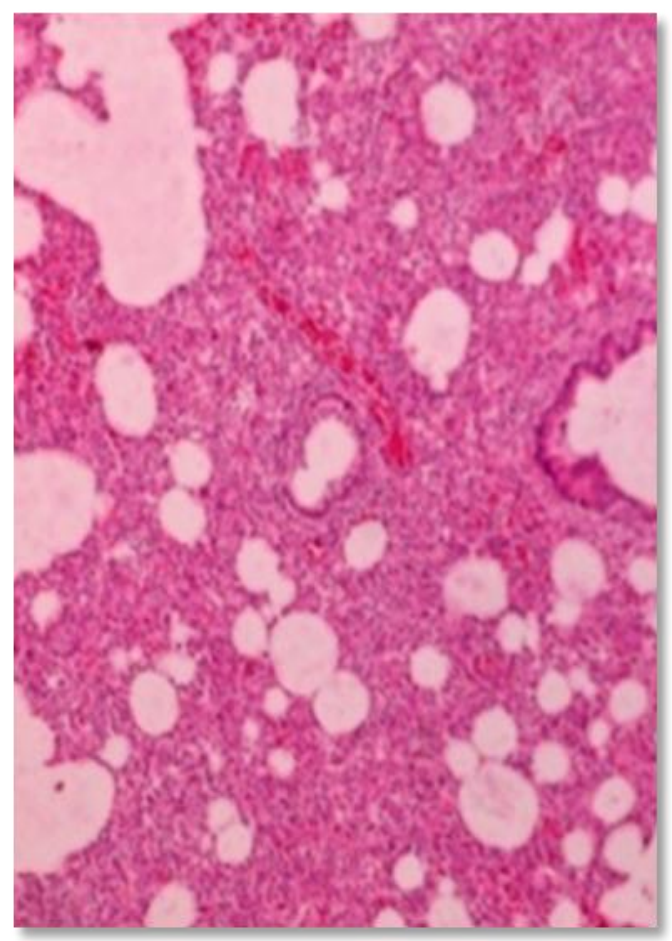

Fig.7 Lung-Interstitium haemorrhages (H\&Ex100)

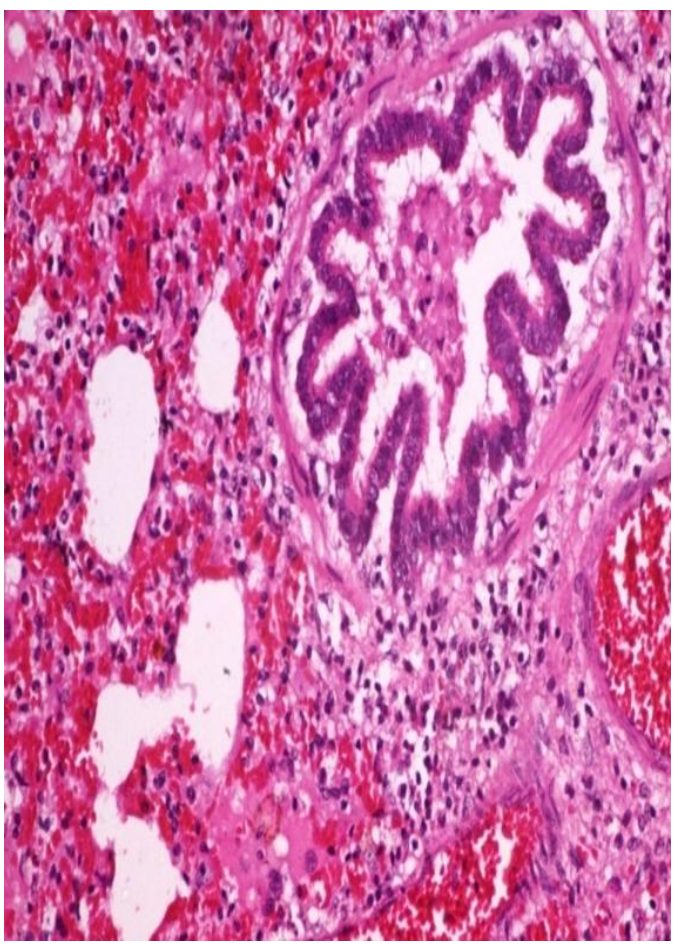

Fig.6 Lung-Broncho-interstitial pneumonia (H\&E x 400)

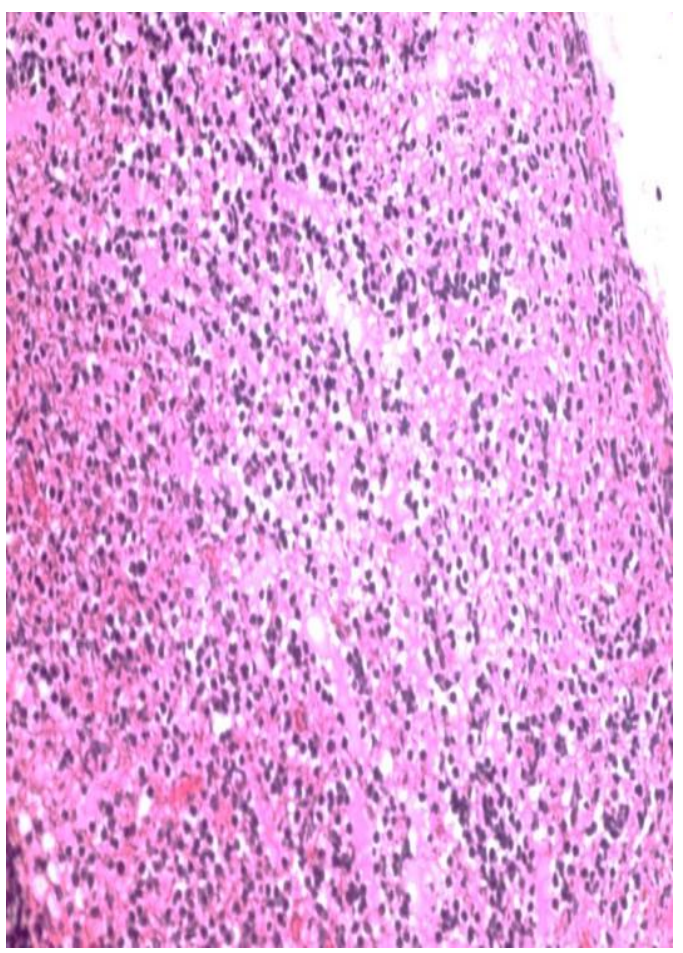

Fig.8 Bronchial lymph node-Severe lymphoid depletion (H\&E x 400) 
Fig.9 fliC gene based Salmonella choleraesuis specific PCR

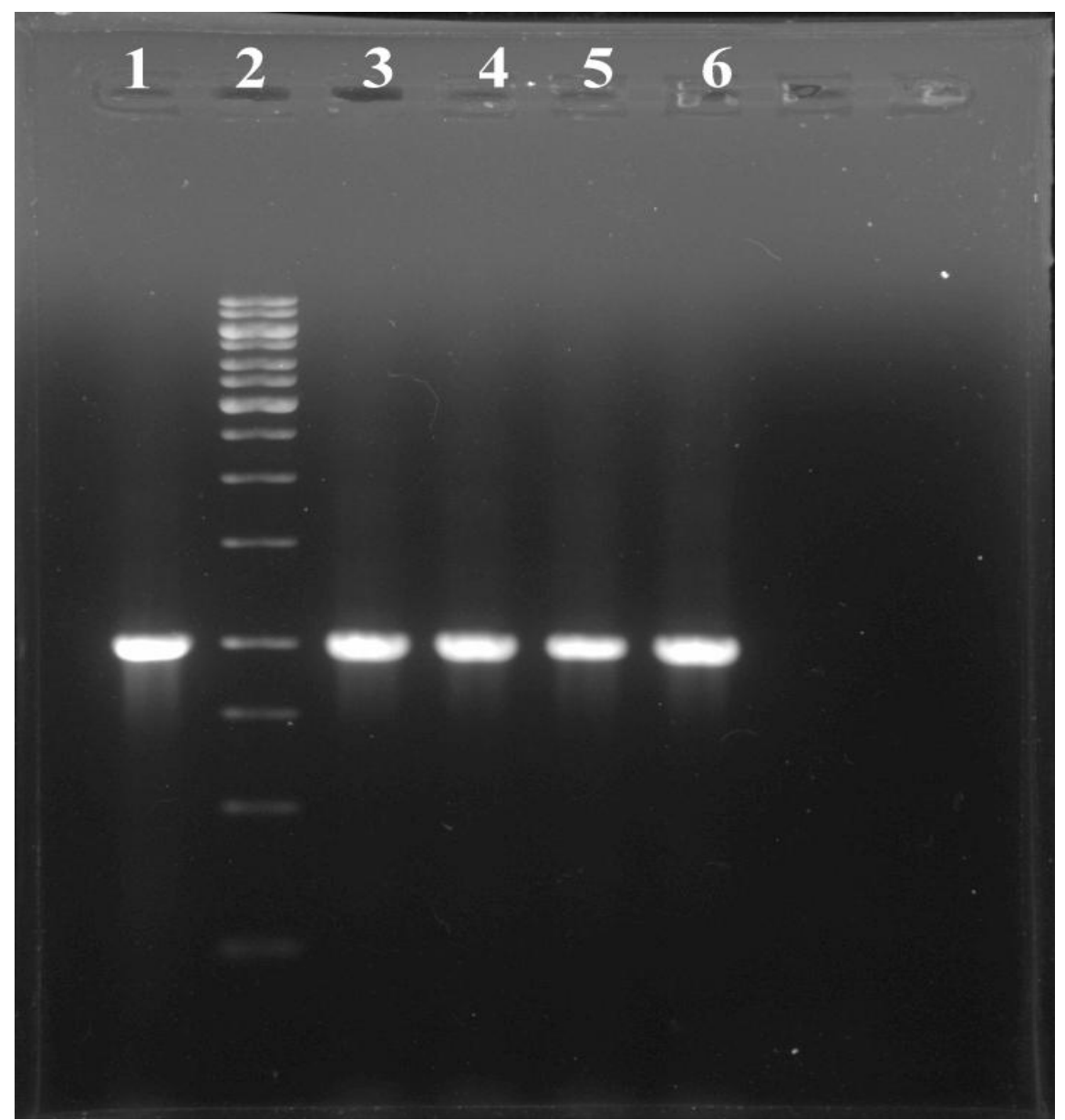

Lane 1, 3, 4, 5, 6 - Samples

Lane 2-1 kbp DNA ladder

On postmortem examination, piglets revealed cyanosis of ear, snout, feet and ventral abdomen. Lungs were voluminous and characterized by the presence of severe oedema, congestion, cranio-ventral consolidation and marked areas of emphysema (Figure 3). Bronchial lymph nodes were congested and enlarged. The presence of froth in tracheal lumen was also observed. These finding were in accordance with those reported by Baskerville and Dow (1973), Carlson et al., (2012), Karanja et al., (2013) and Bose (2015).

Microscopically, presence of oedema in the alveolar lumen and interlobular septum was observed (Figure 5). Interstitial pneumonia characterized by infiltration of mononuclear inflammatory cells, oedema and haemorrhages were noticed in interstitium (Figure 7). Mild to moderate thickening of interlobular septa with proliferation of fibroblast, oedema and infiltration of inflammatory cells were evident. Necrotic debris with eosinophilic exudates was observed in the bronchial and bronchiolar lumen (Figure 6). Bronchial lymph nodes showed moderate to severe lymphoid depletion (Figure 8). This was in accordance with the findings of Bakerville and Dow (1973), Carlson (2012), Karanja et al., (2013) and Bose (2015). LPS component of 
Salmonella species is responsible for the vascular damage and thrombosis which in turn led to the increased permeability of vascular endothelium leading to osmotic imbalance and oedema (Carlson, 2012). Lopez (2012) stated that the oedema is an integral part of early inflammation due to the action of leukotrienes, cytokines and other vasoactive amine released by the inflammatory cells and epithelial cells. Bose (2015) stated that emphysematous changes could be a compensatory mechanism of lung alveoli in occlusions. In the present study also various lesions as observed in the lung could be attributed to the toxic and inflammatory effects of infection.

Thus the present study clearly shows lung is an important organ for the colonization of $S$. choleraesuis infection which may play an important role in pathogenesis. Molecular technique such as PCR could provide rapid and sensitive detection of $S$. choleraesuis and offer advantage over culture methods which would help in timely identification.

\section{Acknowledgement}

The authors of this paper are very much thankful to the Department of Veterinary Pathology and Department of Veterinary Microbiology, College of Veterinary and Animal Science, Mannuthy, Thrissur, Kerala.

\section{References}

Bahadur, D.L., Prasad, D.I., Kumar, Y.S., Md, A. and Zohorul, I.M., 2016. Prevalence and antibiotic resistance profile of Salmonella from livestock and poultry raw meat, Nepal. Int. J. of Mol. Vet. Res.6:1-27.

Bancroft, J.D. and Cook, H.C. 1995. Manual of Histological techniques and their Diagnostic Applications. (2 $2^{\text {nd }}$ Ed.). Churchil Livingstone, Edingburg, 457p.
Baskerville, A. and Dow, C., 1973. Pathology of experimental pneumonia in pigs produced by Salmonella cholerae-suis. J. of Comp. Path.83(2), pp.207-215.

Bose, C., 2015. Bacterial etiopathology of pulmonary infections in piglets. M.V.Sc thesis, Kerala Veterinary and Animal Sciences University, Pookode, 73p.

Carlson, S.A., Barnhill, A.E. and Griffith, R.W. 2012. Salmonellosis. In: Zimmerman, J.J.(ed.), Diseases of swine. $\left(10^{\text {th }}\right.$ Ed.). John Wiley \& sons, Inc. West Sussex, UK, pp. 821-840.

Chiu, C.H., Wu, T.L., Su, L.H., Chu, C., Chia, J.H., Kuo, A.J., Chien, M.S. and Lin, T.Y. 2002. The emergence in Taiwan of fluoroquinolone resistance in Salmonella enterica serotype choleraesuis. New England J.Med. 346: 413-419.

Chiu, T., Pang, J., Hwang, W. and Tsen, H. 2005. Development of PCR primers for the detection of Salmonella enterica Serovar choleraesuis based on the fliC gene. J. Food Prot. 68: 94-99.

Cockerill, F.R., Patel, J.B., Alder, J., Bradford, P.A., Dudley, M.N., Eliopoulos, G.M., Hardy, D.J., Hecht, D.W., Hindler, J.F., Powell, M., Swenson, J.M., Thomson, R.B., Traczewski, M.M., Turnidge, J.D., Weinstein, M. P. and Zimmer, B. L. 2013. Performance Standards for Antimicrobial Susceptibility Testing; Twenty Third Informational Supplements. Clin. Lab. Std. Inst. 33: 45-49.

Dosen, R., Prodanov, J., Milanov, D., Stojanov, I. and Pusic, I. 2007. The bacterial infections of respiratory tract of swine. Biotech. in Anim. Husb. 23: 237-243.

Fedorka-Cray, P.J., Kelley, L.C., Stabel, T.J., Gray, J.T. and Laufer, J.A., 1995. Alternate routes of invasion may affect pathogenesis of Salmonella 
typhimurium in swine. Infection and Immun. 63(7): 2658-2664.

Foley,S.L.,Lynne,A.M.

and

Nayak,R.2008.Salmonella challenges:

prevalence in swine and poultry and potential pathogencity of such isolates.J.Anim.Sci.86(14):149-162.

Irimie, S.M., Herman, V., Pascu, C., Costinar, L., Faur, B., Surpat, A.S., Serbescu, M. and Văduva, I. 2010. Characterization of Salmonella strains isolated from weaned pigs. Lucrări Stiintifice Medicină Veterinară. 43:177.

Jean, S., Wang, J. and Hsueh, P. 2006. Bacteremia caused by Salmonella enterica serotype choleraesuis in Taiwan. J. Microbiol. Immunol. Infection. 39: 358-362.

Karanja, D.N., Ngatia,T.A., Wabacha, J.K. and Bebora,L.C. 2013.Systemic porcine salmonellosis: A potential zoonosis and cause of mortalityin small holderpig farm in Kenya. Tanzania Vet. J. Avialable: http://www.ajol.info/index. php/tvj/article/view/98535/

Lopez, A. 2012. Respiratory system, mediastinum, and pleurae. In: Zachary, J.F. and McGavin, M.D. Pathologic Basis of Veterinary Disease ( $5^{\text {th }}$ Ed.). Elsevier-Mosby, Missouri. pp: 458-538.

Luna, L.G. 1968. Manual of Histologic Staining Methods of the Armed Forces Institute of Animals, ( $3^{\text {rd }}$ Ed.). McGrawHill Book Company, New York, pp. 518.
Nikbakht, B. and Sani, A.M. 2016. Identification of Salmonella sps. from contaminated meat samples by multiplex PCR based assay. J. Exp. Biol. 4: 5-8.

Quinn, P.J., Carter, M.E., Morkry, B. and Carter, C.R. 1994. Clinical Veterinary Microbiology. Mosby Year book Europe Ltd. London, 223p.

Sakano,C., Morita,Y., Goto,K., Yokota., Annaka,H., Fujita,M., Kobatake,S., Ishioka,T., Hoshino, T., Boonmar,S., Pulsrikarn,C., Nishina,A., Kozawa,K., Yamamoto,S. and Kimura,H. 2011. Prevalence and Genotype of Salmonella choleraesuis in Gunma Prefeccture, Japan.Thai. J.Vet. Med. 41(3): 321-326.

Wolf, P.J.V., Bongers, J.H., Elbersa, A.R.W., Franssena, F.M.M.C., Hunnemana, W.A., Exsela, A.C.A. and Tielena, M.J.M. 1999. Salmonella infections in finishing pigs in The Netherlands: bacteriological herd prevalence, serogroup and antibiotic resistance of isolates and risk factors for infection. Vet. Microbiol.67:263-275.

Zottola, T., Montagnaro, S., Magnapera, C., Sasso, S., De Martino, L., Bragagnolo, A., D'Amici, L., Condoleo, R., Pisanelli, G., Iovane, G. and Pagnini, U. 2013. Prevalence and antimicrobial susceptibility of Salmonella in European wild boar (Sus scrofa); Latium Region - Italy. Comp. Immunol. Microbiol. Infect. Dis. 36: 161-168.

\section{How to cite this article:}

Geethika, A., Mammen J. Abraham, N. Divakaran Nair, K. Krithiga and Priya, P.M. 2017. Pathology of Salmonella choleraesuis Related Respiratory Infection in Piglets, Its Isolation, Identification and Antibiogram. Int.J.Curr.Microbiol.App.Sci. 6(10): 3166-3173. doi: https://doi.org/10.20546/ijcmas.2017.610.371 